\title{
Crescimento de folhas do capim-bermuda tifton 85 submetido à adubação nitrogenada após o corte
}

\author{
Linda Monica Premazzi ${ }^{1}$, Francisco Antonio Monteiro ${ }^{2}$, Ricardo Ferraz de Oliveira ${ }^{3}$ \\ 1 Programa de Pós-Graduação em Solos e Nutrição de Plantas/Departamento de Ciência do Solo - ESALQ/USP. Caixa Postal 09, 13418-900, \\ Piracicaba, SP. \\ 2 Departamento de Ciência do Solo - ESALQ/USP. Caixa postal 09, 13418-900, Piracicaba, SP. \\ ${ }^{3}$ Departamento de Ciencias Biológicas - ESALQ/USP. Caixa postal 09, 13418-900, Piracicaba, SP.
}

RESUMO - Com o objetivo de avaliar a influência de doses e épocas de aplicação de nitrogênio após o corte no fator de correção de área foliar, na taxa de alongamento de folhas e no comprimento e área da lâmina foliar do capim-bermuda tifton 85 (Cynodon spp) foram conduzidos dois experimentos em casa de vegetação. Ambos os experimentos foram estabelecidos em vasos com capacidade para $7 \mathrm{~kg}$ de terra, com solo classificado como Neossolo Quartzarênico Órtico típico, em esquema fatorial $4 \times 2$, para avaliação de quatro doses de nitrogênio (0, 80, 160 e $240 \mathrm{mg} \mathrm{kg}^{-1}$ de solo) e duas épocas de aplicação (imediatamente após o corte e sete dias após o corte das plantas). O delineamento experimental foi em blocos completos ao acaso, com quatro repetições. Com o fornecimento de nitrogênio, observou-se diminuição no fator de correção de área foliar. O nitrogênio proporciona variação positiva no comprimento foliar, na área da lâmina foliar e na taxa de alongamento da folha, variações que ocorreram em maior grandeza entre a não-aplicação de nitrogênio e a dose de $80 \mathrm{mg} \mathrm{kg}^{-1}$ de solo.

Palavras-chave: alogamento da folha, área foliar, comprimento foliar, Cynodon

\section{Leaf growth of tifton 85 bermudagrass submitted to nitrogen fertilization after cutting}

\begin{abstract}
With the objective of evaluating the influence of nitrogen rates and application time after cutting on correction factor for leaf area, on leaf elongation rate and on blade leaf length and area of tifton 85 bermudagrass (Cynodon spp), two experiments were carried out in a greenhouse. Both experiments were established in pots with capacity for $7 \mathrm{~kg}$ of soil classified as Entisol, in a $4 \times 2$ factorial scheme, for evaluation of four nitrogen rates (0, 80, 160 and $240 \mathrm{mg} \mathrm{kg}^{-1}$ of soil) and two application times (immediately after cutting and seven days after cutting of the plants). It was used a complete randomized block design, with four replications. As nitrogen was supplied, it was observed a decrease in the correction factor for leaf area. There is a predominance of positive effects of nitrogen on leaf length, on leaf blade area and on leaf elongation rate. Great nitrogen effect was observed when comparying no-nitrogen application with the rate of $80 \mathrm{mg} \mathrm{kg}^{-1}$ of soil.
\end{abstract}

Key Words: leaf elongation, leaf area, leaf length, Cynodon

\section{Introdução}

O suprimento de nitrogênio influencia a produção da forragem, principalmente por seu efeito no tamanho da folha, o que ocorre tanto nas plantas individualmente quanto no dossel (Whitehead, 1995).

Considerando gramíneas de clima temperado, há consenso quanto aos resultados positivos do fornecimento de nitrogênio no crescimento das folhas: com azevémperene (Lolium perenne), foram constatados variação de $33 \%$ na taxa de alongamento de folhas (Robson \& Deacon, 1978) e aumento de três e cinco vezes na taxa de expansão foliar e no comprimento da lâmina foliar, respectivamente
(Pearse \& Wilman, 1984); com azevém-italiano (Lolium multiflorum), Wilman et al. (1977) observaram aumento de $34 \%$ na largura da folha, de $99 \%$ no comprimento e de $171 \%$ na área foliar; com festuca (Festuca arundinacea), foram constatados desde acréscimos de 15 a $28 \%$ na taxa de alongamento das folhas (Mazzanti et al., 1994) até aumentos de $89 \%$ (Volenec \& Nelson, 1983), atingindo valores 3 a 4 vezes maiores na taxa de expansão foliar (Gastal et al., 1992).

Pesquisas com gramíneas tropicais confirmam a ação do nitrogênio no crescimento das folhas. Em relação à nãoaplicação de nitrogênio, acréscimos na taxa de alongamento das folhas foram observados por Garcez Neto et al. (2002) para o capim-mombaça (Panicum maximum cv. Mombaça), 
de 52, 92 e 133\%; por Alexandrino et al. (2004) com capim-marandu (Brachiaria brizantha cv. Marandu), de 185 e 264\%; por Martuscello et al. (2005) com capim-xaraés (Brachiaria brizantha cv. Xaraés) e por Martuschello et al. (2006) com capim-massai (P. maximum $\times$ P. maximum infestum cv. Massai) de até 37 e $64 \%$, respectivamente. Aumentos de até 130 e $116 \%$ na área foliar foram observados por Martuscello et al. (2005) e Martuschello et al. (2006), respectivamente.

A determinação da área da lâmina foliar pode ser realizada de maneira indireta. Nesse caso, medidas lineares de comprimento e de largura da lâmina foliar são tomadas diretamente nas folhas e a área obtida pelo produto dessas medidas é corrigida por um fator de correção de área foliar. Kemp (1960) e Schiavuzzo et al. (1998) determinaram em gramíneas valores de 0,905 e 0,835 para esse fator, respectivamente.

Objetivou-se verificar a influência de doses de nitrogênio fornecido em duas épocas de aplicação após o corte no valor do fator de correção de área foliar e no crescimento das folhas no capim-bermuda tifton 85 .

\section{Material e Métodos}

Dois experimentos foram conduzidos com capimbermuda tifton 85 (Cynodon spp) em casa de vegetação localizada no município de Piracicaba, São Paulo. Os experimentos foram estabelecidos em esquema fatorial $4 \times 2$, sendo avaliadas quatro doses de nitrogênio e duas épocas de aplicação após o corte das plantas. O delineamento experimental foi o de blocos completos ao acaso, com quatro repetições. $\mathrm{O}$ nitrogênio foi fornecido na forma de $\mathrm{NH}_{4} \mathrm{NO}_{3}$, nas doses de $0,80,160$ e $240 \mathrm{mg} \mathrm{kg}^{-1}$ de solo. As duas épocas de aplicação do nitrogênio foram imediatamente após o corte e sete dias após o corte.

O solo utilizado é classificado como Neossolo Quartzarênico Órtico típico, com horizonte A moderado álico fase cerrado (Embrapa, 1999). Utilizaram-se vasos com capacidade para $7 \mathrm{~kg}$ de solo. Na análise do solo, foram obtidos os seguintes valores: $\mathrm{pH}$ em $\mathrm{CaCl}_{2}=3,95$; $\mathrm{P}=$ $1,6 \mathrm{mg} \mathrm{dm}^{-3}$; matéria orgânica $=15,9 \mathrm{~g} \mathrm{dm}^{-3} ; \mathrm{K}^{+}=0,3$; $\mathrm{Ca}^{2+}=0,6 ; \mathrm{Mg}^{2+}=0,5 ; \mathrm{H}+\mathrm{Al}=47 ; \mathrm{Al}^{3+}=7 ;$ soma de bases trocáveis $=1,4 ;$ CTC $=48,4$ (concentrações essas expressas em $\mathrm{mmol}_{\mathrm{C}} \mathrm{dm}^{-3}$ ) e V\% $=2,89$. A acidez do solo foi corrigida utilizando-se o valor $\mathrm{V}_{2}$ de $60 \%$ para a saturação por bases do solo e efetuando-se a aplicação de $\mathrm{CaO}$ e $\mathrm{MgO}$. Sete mudas do capim foram transplantadas em cada vaso 50 dias após a incubação do solo. Onze dias após o plantio foi realizado o primeiro corte $(4,5 \mathrm{~cm}$ de altura) de uniformização das plantas seguindo-se a aplicação de nutrientes (em mg kg-1 de solo) $\mathrm{P}=100, \mathrm{~K}=125$ e $\mathrm{N}=10$ e um segundo corte de uniformização foi realizado vinte dias após o primeiro (2,5 cm de altura) com a aplicação de nitrogênio de $10 \mathrm{mg} \mathrm{kg}^{-1}$ de solo. A coleta de resultados foi iniciada em 24 de março com o corte das plantas a 2,5 cm de altura, quando foram aplicadas as doses de nitrogênio e a adubação que se constituiu dos seguintes nutrientes (em $\mathrm{mg} \mathrm{kg}^{-1} \mathrm{de}$ solo) $\mathrm{P}=100 ; \mathrm{K}=125,8 ; \mathrm{S}=8$; $\mathrm{B}=0,25 ; \mathrm{Cu}=1,0 ; \mathrm{Zn}=1,0$ e $\mathrm{Mo}=0,1$.

Os dois experimentos foram conduzidos simultaneamente. A coleta de resultados em ambos os experimentos foi realizada em dois períodos de crescimento das plantas: o primeiro entre 24 de março e 2 de maio (39 dias) e o segundo, entre 3 de maio a 13 de junho (41 dias). Cada período de crescimento foi marcado pelo corte das plantas e pelo fornecimento de nitrogênio, em uma única aplicação, nas doses e épocas respectivas.

No primeiro experimento, avaliou-se a variação do fator de correção de área foliar com o fornecimento de nitrogênio. Calculou-se a relação entre a área da lâmina foliar determinada no medidor portátil (Modelo LI-3000 A) e a área obtida pela multiplicação das medidas de comprimento pela largura da lâmina foliar. Essa relação foi identificada como fator F.

Foram realizadas duas determinações, uma no primeiro (8 de abril) e outra no segundo (22 de maio) período de crescimento das plantas, quando as plantas tinham 15 e 20 dias de crescimento, respectivamente. Em cada determinação, foram coletadas lâminas foliares de folhas completamente expandidas, de tamanho médio (em relação ao tamanho das folhas presentes), de plantas distintas em cada vaso. Foram coletadas dez lâminas foliares na primeira e seis na segunda avaliação. A coleta foi sempre às 6 h30, quando as folhas se encontravam túrgidas. As lâminas foliares foram ensacadas individualmente e procedeu-se à medição do comprimento (do ápice até a base da lâmina) e da largura (sendo esta determinada na sua parte mais larga). Em seguida, essas mesmas folhas foram encaminhadas para determinação de suas áreas foliares no medidor portátil, e foram efetuados os respectivos cálculos do fator $\mathrm{F}$, em que: $\mathrm{F}$ = área determinada no medidor portátil/comprimento $\times$ largura da folha.

No segundo experimento, determinaram-se o comprimento da lâmina foliar, a área foliar e a taxa de alongamento da folha, que foram avaliados em uma folha por planta, em quatro plantas distintas em cada vaso, sendo que, em cada período de crescimento, foram realizadas duas avaliações. No primeiro período de crescimento a primeira e segunda avaliações foram iniciadas, respectivamente, nos dias 3 e 11 de abril, enquanto, no segundo crescimento, a terceira e a quarta 
avaliações tiveram início em 13 e 19 de maio. A folha mais nova de cada planta foi tomada como folha padrão de medição. A folha imediatamente anterior a esta foi marcada com tinta, como referência à folha padrão de medição. $\mathrm{O}$ comprimento da folha, tomado diretamente nas plantas, foi obtido pela medida entre a ponta da folha e o ponto de inserção da folha expandida surgida imediatamente antes da folha padrão de medição (Gastal et al., 1992). Nesse tipo de medição, a bainha é incluída na medida do comprimento da folha. As folhas foram medidas a cada dois dias até sua completa expansão, a qual foi determinada pelo aparecimento da lígula (Andrews et al., 1991). A taxa de alongamento da folha foi obtida pela diferença em comprimento entre as medições realizadas a cada dois dias.

Por ocasião do aparecimento da lígula, foram também determinados o comprimento, a largura e a área da lâmina foliar. Nessa avaliação, o comprimento da lâmina foliar foi medido entre sua ponta até a lígula e a largura da lâmina foi medida na sua parte mais larga. A multiplicação do comprimento pela largura permitiu estimar a área da lâmina foliar, cujo valor foi multiplicado pelo fator de correção (F) para fornecer a área real da lâmina foliar.

Foi realizada análise de variância para verificar a significância do efeito de doses e de épocas de aplicação de nitrogênio na taxa de alongamento da folha, no comprimento da lâmina foliar e na área foliar. Os resultados para as doses de nitrogênio foram ajustados a modelos linear e quadrático e o efeito da época foi avaliado por meio do teste Tukey. Foi utilizado o software SAS para Windows, versão 6.11, adotando-se o nível de 5\% de significância e apresentando os efeitos que foram significativos.

\section{Resultados e Discussão}

A análise de variância mostrou efeito significativo das doses de nitrogênio no fator de correção de área foliar. Esse efeito foi representado por equações de segundo e primeiro grau, respectivamente, no primeiro e segundo crescimentos (Figura 1).

No primeiro crescimento, o fator de correção decresceu com o aumento na dose de nitrogênio até $154 \mathrm{mg} \mathrm{kg}^{-1} \mathrm{de}$ solo, quando o valor do fator atingiu o mínimo estimado de 0,77 . O valor máximo estimado de 0,83 para o fator, em ambos os períodos de crescimento do capim-bermuda tifton 85 na não-aplicação de nitrogênio, foi muito próximo do valor de 0,835 obtido para o capim-marandu por Schiavuzzo et al. (1998), que não constataram variação nesse fator com as doses de nitrogênio.

Valores inferiores para o capim-bermuda tifton 85 em relação ao capim-marandu decorrem provavelmente de

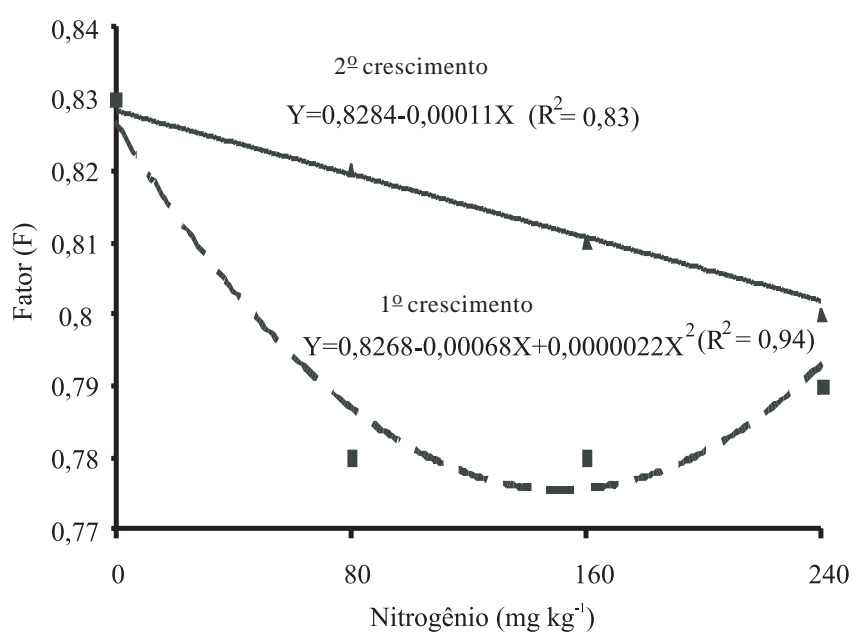

Figura 1 - Fator de correção de área foliar do capim-bermuda tifton 85, no primeiro e segundo crescimentos, em função das doses de nitrogênio.

diferenças na morfologia da lâmina foliar das duas espécies forrageiras. Kemp (1960) observou que o modelo da folha diferiu consideravelmente entre as espécies, com as folhas de azevém-perene apresentando a proporção entre comprimento e largura foi duas vezes maior que em Dactylis glomerata. O efeito do nitrogênio no crescimento das folhas, em comprimento e área foliar, depende da espécie considerada (Andrews et al., 1991). Esses autores verificaram em Phalaris aquatica valores de 69 e $76 \mathrm{~mm}$ para comprimento e de 160 e $213 \mathrm{~mm}^{2}$ para área foliar, enquanto os valores observados foram de 91 e $90 \mathrm{~mm}$ e de 132 e $176 \mathrm{~mm}^{2}$ para azevém-perene, com as doses de nitrato de 0,5 e $5,0 \mathrm{~mol} \mathrm{~m}^{-3}$, respectivamente.

A partir das equações de regressão (Figura 1), estimaram-se os valores do fator F de 0,$83 ; 0,79 ; 0,77$ e 0,79 para o primeiro crescimento e 0,$83 ; 0,82 ; 0,81$ e 0,80 para o segundo crescimento, em função das doses de nitrogênio de 0 ; 80; 160 e $240 \mathrm{mg} \mathrm{kg}^{-1}$ de solo, respectivamente. A variação nos valores, entre 0,83 e 0,79 no primeiro crescimento e entre 0,83 e 0,80 no segundo crescimento, mostra a consistência dos resultados. Os valores de F estimados a partir das equações regressão, para cada dose de nitrogênio e período de crescimento, foram respectivamente utilizados no cálculo da área foliar a partir das medidas de comprimento e largura tomadas diretamente nas plantas.

Para o comprimento e a área da lâmina foliar do capim-bermuda tifton 85 , foi significativa a interação doses de nitrogênio × épocas de aplicação de nitrogênio. O comprimento de lâmina foliar na primeira e segunda avaliações e a área da lâmina foliar na primeira avaliação foram significativamente alterados pelas doses de nitrogênio. Para o comprimento da lâmina foliar na terceira 
e quarta avaliações e para área da lâmina foliar na segunda, terceira e quarta avaliações, foi observada significância para a interação doses de nitrogênio $\times$ épocas de aplicação desse nutriente.

$\mathrm{Na}$ primeira e segunda avaliações do primeiro crescimento do capim-bermuda tifton 85, a variação significativa no comprimento da lâmina foliar proporcionada pelas doses de nitrogênio traduziu-se em modelos quadráticos de regressão e os máximos valores estimados para essa variável foram de 193 e $158 \mathrm{~mm}$, obtidos com aplicação de nitrogênio de 162 e $187 \mathrm{mg} \mathrm{kg}^{-1}$ de solo,
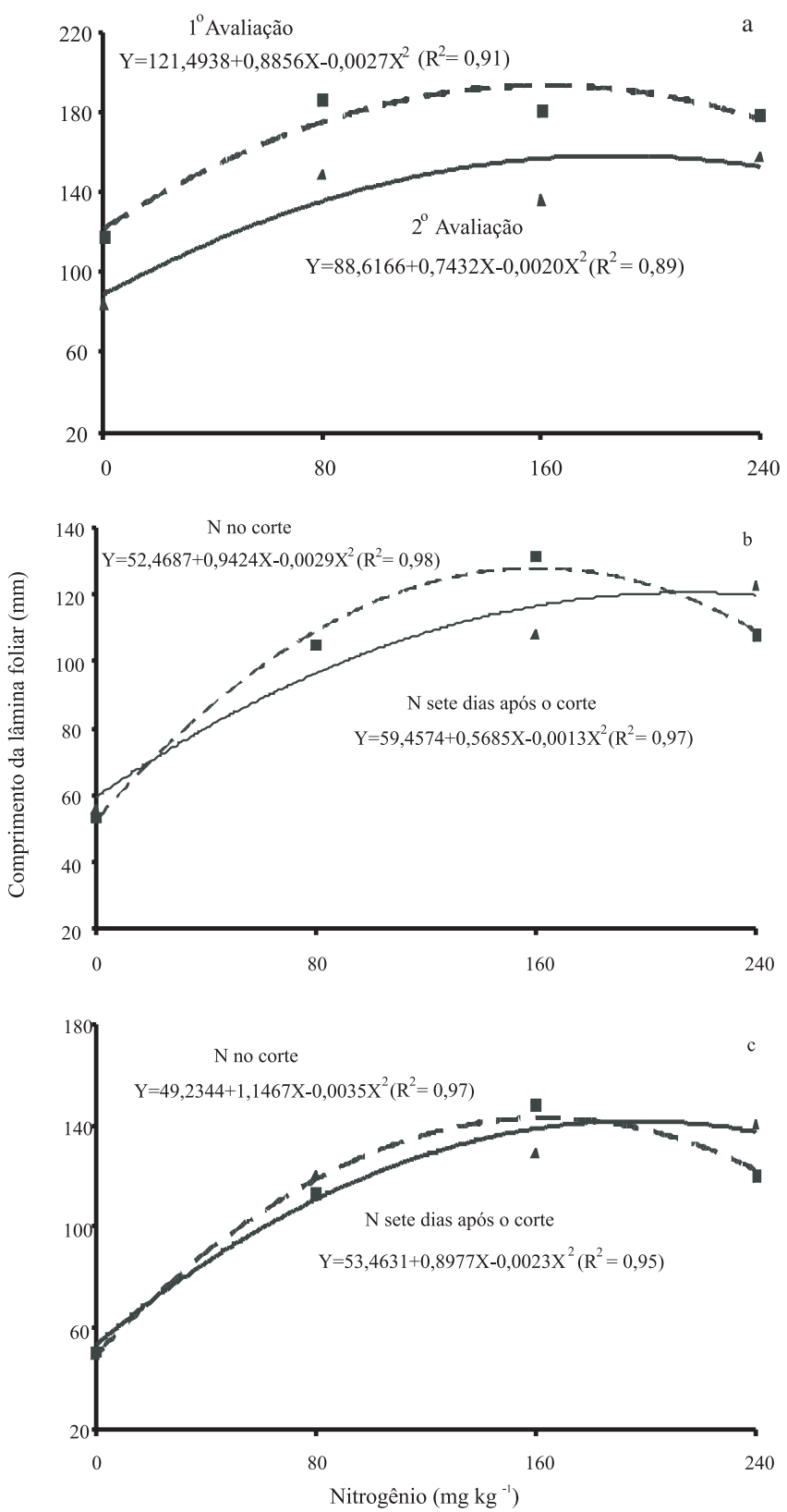

Figura 2 - Comprimento da lâmina foliar do capim-bermuda tifton 85 na primeira e segunda (a) e na terceira (b) e quarta (c) avaliações, em função das doses de nitrogênio. respectivamente (Figura 2a). No segundo crescimento, o desdobramento da interação mostrou efeito significativo das doses de nitrogênio, nas duas épocas de fornecimento, o qual foi representado por modelo quadrático de regressão.

Na terceira avaliação (Figura 2b), os valores máximos estimados para comprimento da lâmina foliar, de 128 e $121 \mathrm{~mm}$, foram obtidos nas doses de nitrogênio de 160 e $215 \mathrm{mg} \mathrm{kg}^{-1}$ de solo, quando o nitrogênio foi aplicado no momento do corte e sete dias após, respectivamente. $\mathrm{Na}$ quarta avaliação, estimaram-se os valores máximos de 143 e 142 mm para comprimento da lâmina foliar, que foram alcançados nas doses de nitrogênio de 163 e $197 \mathrm{mg} \mathrm{kg}^{-1}$ de solo considerando a aplicação de nitrogênio no momento do corte e sete dias após, respectivamente (Figura 2c).

Considerando a dose de nitrogênio de $160 \mathrm{mg} \mathrm{kg}^{-1}$ de solo, observou-se também efeito significativo das épocas de aplicação de nitrogênio no comprimento foliar, quando foram observados valores de 132 e $108 \mathrm{~mm}$ na terceira avaliação e de 148 e 129 mm na quarta avaliação, considerando a aplicação de nitrogênio no momento do corte e sete dias após, respectivamente.

Para a área da lâmina foliar, na primeira avaliação, verificou-se significância para as doses de nitrogênio, cujos resultados ajustaram-se a modelo quadrático, com o máximo valor estimado de $845 \mathrm{~mm}^{2}$ obtido na dose de nitrogênio de $165 \mathrm{mg} \mathrm{kg}^{-1}$ de solo (Figura 3a). Na segunda, terceira e quarta avaliações, observou-se significância da interação doses de nitrogênio × épocas de aplicação de nitrogênio após o corte, cujo desdobramento mostrou efeito significativo das doses de nitrogênio em ambas as épocas de fornecimento. Na segunda avaliação, esse efeito foi representado por um modelo linear de regressão quando o nitrogênio foi aplicado no momento do corte e por um modelo quadrático quando o nitrogênio foi aplicado sete dias após o corte, obtendo-se valor máximo de $765 \mathrm{~mm}^{2}$ na dose de nitrogênio de $162 \mathrm{mg} \mathrm{kg}^{-1}$ de solo (Figura 3b). Na dose de nitrogênio de $80 \mathrm{mg} \mathrm{kg}^{-1}$ de solo, observou-se também efeito significativo das épocas de aplicação de nitrogênio, obtendo-se os valores de 585 e 793 mm² quando a adubação foi realizada no momento do corte e sete dias após o corte, respectivamente.

No segundo crescimento, modelos de segundo grau representaram os efeitos das doses de nitrogênio na área foliar dentro das épocas de aplicação. Na terceira avaliação, os valores máximos estimados de área da lâmina foliar, de 594 e $573 \mathrm{~mm}^{2}$, foram obtidos nas doses de nitrogênio de 166 e $226 \mathrm{mg} \mathrm{kg}^{-1}$ de solo quando o nitrogênio foi aplicado no momento do corte e sete dias após, respectivamente 
(Figura 3c). Na quarta avaliação, os valores máximos estimados de área da lâmina foliar foram de 614 e 645 mm² $^{2}$ e foram encontrados nas doses de nitrogênio de 173 e $194 \mathrm{mg} \mathrm{kg}^{-1}$ de solo, quando o nitrogênio foi aplicado no momento do corte e sete dias após o corte, respectivamente (Figura 3d).

Na terceira e quarta avaliações, foi verificado efeito significativo das épocas de fornecimento de nitrogênio na área da lâmina foliar, em determinadas doses de nitrogênio. Na terceira avaliação, esse efeito foi observado na dose de nitrogênio de $160 \mathrm{mg} \mathrm{kg}^{-1}$ de solo e valores de 607 e $493 \mathrm{~mm}^{2}$ de área foliar foram verificados quando o nitrogênio foi aplicado no momento do corte e sete dias após, respectivamente. Na quarta avaliação, o efeito da época de aplicação do nitrogênio foi observado nas doses de nitrogênio de 80 e $240 \mathrm{mg} \mathrm{kg}^{-1}$ de solo, alcançando-se os valores de 449 e $537 \mathrm{~mm}^{2}$ e de 526 e $638 \mathrm{~mm}^{2}$ quando se considerou a aplicação de nitrogênio no momento do corte e sete dias após, respectivamente.

A taxa de alongamento das folhas no primeiro crescimento do capim foi significativamente afetada tanto pelas doses de nitrogênio quanto pelas épocas de aplicação de nitrogênio após o corte. O efeito das doses de nitrogênio foi mostrado por modelo de segundo grau, quando se observou aumento na taxa de alongamento das folhas até as doses de nitrogênio de 156 e $190 \mathrm{mg} \mathrm{kg}^{-1}$ de solo, correspondentes a valores de 59 e $65 \mathrm{~mm} /$ perfilho/2dias para a primeira e segunda avaliações, respectivamente (Figura 4a). As médias obtidas para a aplicação de nitrogênio, imediatamente após o corte e sete dias após foram,

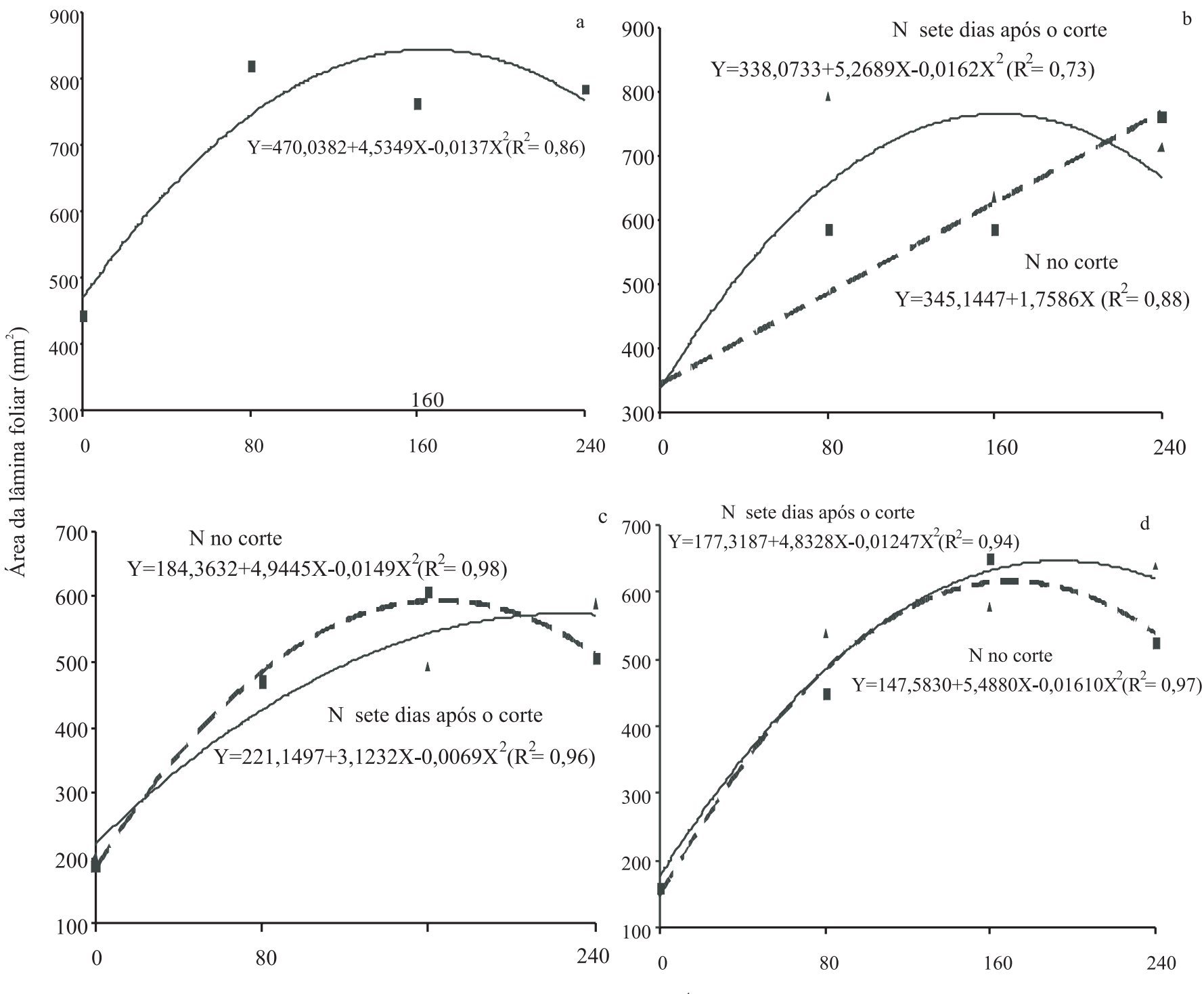

Nitrogênio $\left(\mathrm{mg} \mathrm{kg}^{-1}\right)$

Figura 3 - Área da lâmina foliar do capim-bermuda tifton 85 na primeira (a), segunda (b), terceira (c) e quarta (d) avaliações, em função das doses de nitrogênio. 
respectivamente, de 46 e $41 \mathrm{~mm} /$ perfilho/2dias para a primeira avaliação e de 42 e $49 \mathrm{~mm} /$ perfilho/2dias para a segunda avaliação. Na terceira avaliação constatou-se efeito das doses de nitrogênio representado por modelo quadrático de regressão, com o máximo valor estimado de $52 \mathrm{~mm} /$ perfilho/2dias alcançado na dose de nitrogênio de $165 \mathrm{mg} \mathrm{kg}^{-1}$ de solo (Figura 4b).

Na quarta avaliação, foi observada significância para a interação doses de nitrogênio × épocas de aplicação
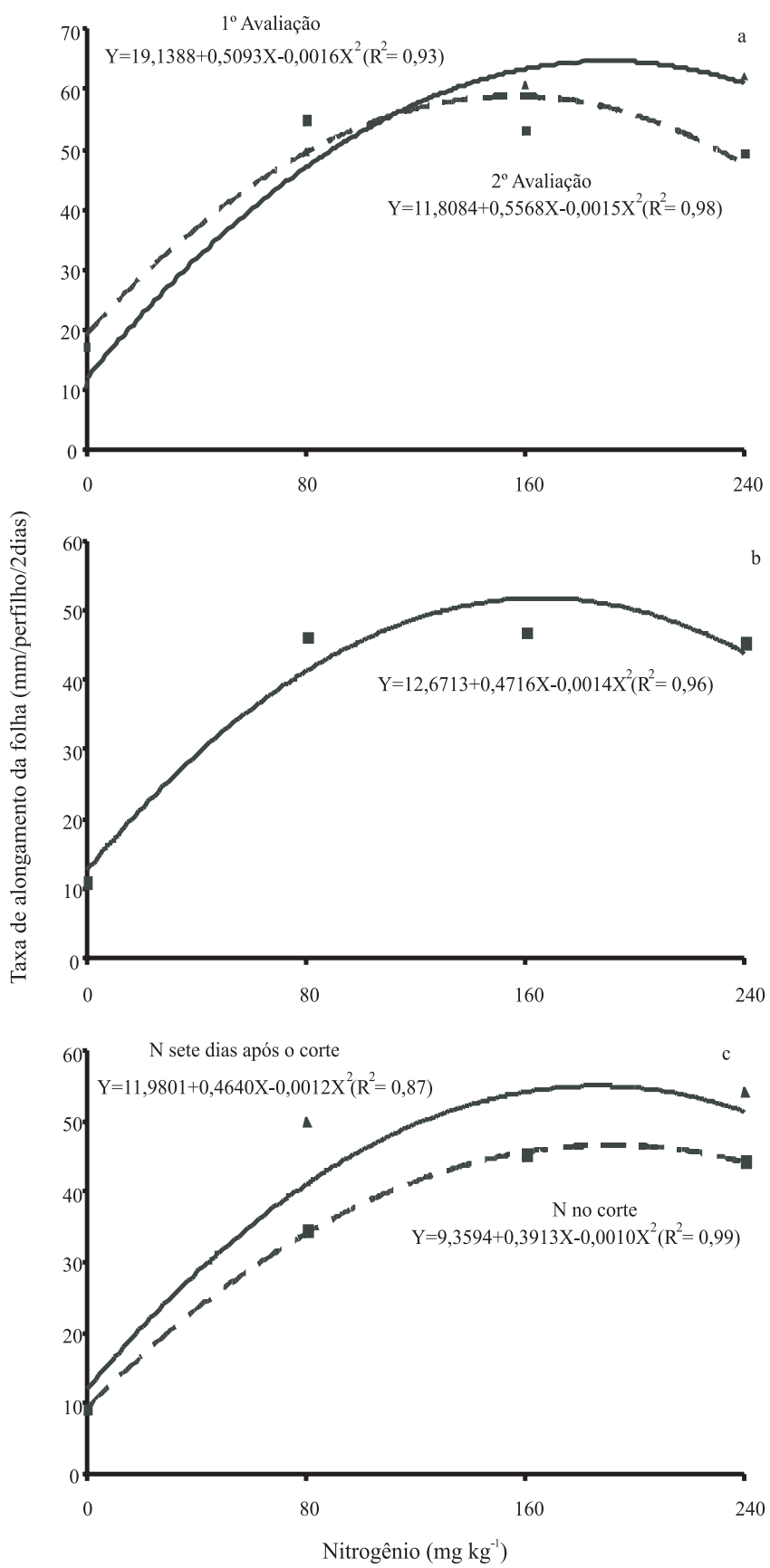

Figura 4 - Taxa de alongamento de folhas do capim-bermuda tifton 85 na primeira e segunda (a), terceira (b) e quarta (c) avaliações em função das doses de nitrogênio. de nitrogênio após o corte. Os máximos valores para taxa de alongamento das folhas (correspondentes a $47 \mathrm{e}$ $55 \mathrm{~mm} /$ perfilho/2dias) foram obtidos nas doses de nitrogênio de 191 e $186 \mathrm{mg} \mathrm{kg}^{-1}$ de solo quando o nitrogênio foi aplicado imediatamente após o corte e sete dias após, respectivamente (Figura 4c). Foi constatado efeito significativo da época de aplicação de nitrogênio nas doses de nitrogênio de 80 e $240 \mathrm{mg} \mathrm{kg}^{-1}$ de solo, quando foram observados os valores de 35 e $50 \mathrm{~mm} /$ perfilho/2 dias para a dose $80 \mathrm{mg} \mathrm{kg}^{-1}$ de solo e de 44 e $54 \mathrm{~mm} /$ perfilho/2 dias para a dose $240 \mathrm{mg} \mathrm{kg}^{-1}$ de solo, para aplicação de nitrogênio após o corte e sete dias após, respectivamente.

Os resultados positivos no crescimento das folhas do capim-bermuda tifton 85 com a aplicação de nitrogênio corroboram os da literatura, devendo-se, contudo, observar alguma variação quanto ao tipo e número de folhas amostradas. As maiores variações em comprimento, área e taxa de alongamento foliares ocorreram entre a não-aplicação de nitrogênio e a dose de $80 \mathrm{mg} \mathrm{kg}^{-1}$ de solo, indicando que o maior limite para o crescimento das folhas esteve, nesta condição experimental, condicionado à aplicação de nitrogênio de até $80 \mathrm{mg} \mathrm{kg}^{-1}$ de solo. De forma similar, Andrews et al. (1991) encontraram para alguns cereais, com fornecimento de nitrato na faixa de 0,1 a $1,0 \mathrm{~mol} \mathrm{~m}^{-3}$, os maiores acréscimos na taxa média de crescimento e comprimento final das folhas, porém esse efeito na área foliar estendeu-se até a dose mais elevada (de 5,0 $\mathrm{mol} \mathrm{m}^{-3}$ ), quando as plantas foram submetidas a concentrações de nitrato de 0,1 a $20 \mathrm{~mol} \mathrm{~m}^{-3}$.

Os valores de comprimento e área da lâmina foliar e de taxa de alongamento da folha variaram de 49 a $121 \mathrm{~mm}$, de 147 a 470 mm² e de 9 a 19 mm/perfilho/2dias na não-aplicação de nitrogênio até os valores máximos estimados de 121 a 193 $\mathrm{mm}$, de 573 até $845 \mathrm{~mm}^{2}$ e de 47 a $59 \mathrm{~mm} /$ perfilho/2dias, respectivamente. Em relação à taxa de alongamento foliar, os valores foram em geral, de mesma grandeza aos observados para gramíneas de clima temperado; comparando-se com gramíneas de clima tropical alguns valores superiores foram observados em relação ao capimbermuda tifton 85 . Volenec \& Nelson (1983) obtiveram, com genótipos de festuca, os valores de 8,1 e 15,3 mm/dia com as doses de nitrogênio de 22 e $336 \mathrm{~kg} \mathrm{ha}^{-1}$, respectivamente. Pearse \& Wilman (1984), com o azevém-perene, relataram valores de 4,2; 8,3 e 12,1 mm/perfilho/dia, quando as aplicações de nitrogênio foram de 0 , 66 e $132 \mathrm{~kg} \mathrm{ha}^{-1}$. Andrews et al. (1991) obtiveram, com a festuca e com azevém-perene, os valores de 6,4 e 8,5 mm/dia e de 9,8 e $8,7 \mathrm{~mm} /$ dia para taxa de expansão média com doses de nitrato que variaram de 0,5 a $5,0 \mathrm{~mol} \mathrm{~m}^{-3}$, respectivamente. Gastal et al. (1992) observaram, quando as doses de 
nitrogênio variaram de 0 até $200 \mathrm{~kg} \mathrm{ha}^{-1}$ na primavera e de 0 até $160 \mathrm{~kg} \mathrm{ha}^{-1}$ no verão, que a taxa de expansão foliar da festuca variou de 2 a $28 \mathrm{~mm} /$ perfilho/dia. Bélanger (1998) obteve para Phleum pratense, mediante fornecimento de nitrogênio de 0 a $210 \mathrm{~kg} \mathrm{ha}^{-1}$ na primavera e de 0 a $180 \mathrm{~kg} \mathrm{ha}^{-1}$ no verão, os valores de 10,5 e $35,8 \mathrm{~mm} /$ perfilho/dia e de 20,7 e $56,8 \mathrm{~mm} /$ perfilho/dia, respectivamente.

Considerando gramíneas de clima tropical, a regressão quadrática expressou os aumentos na taxa de alongamento das folhas pela adição de nitrogênio para o capim-mombaça (Garcez Neto et al., 2002), a partir da qual foi possível estimar os valores de $25,39,49,56$ e $59 \mathrm{~mm} /$ dia para as doses de nitrogênio de 0, 50, 100, 150 e $200 \mathrm{mg} \mathrm{dm}^{-3}$, respectivamente. Alexandrino et al. (2004) obtiveram regressão linear positiva com as doses de nitrogênio de 0 , 20 e $40 \mathrm{mg} \mathrm{dm}^{-3}$, por meio da qual foram estimados os valores de 19, 35 e $50 \mathrm{~mm} /$ perfilho/dia com capim-marandu. Martuschello et al. (2006) constataram resposta positiva ajustada a modelos lineares a partir da qual foi possível estimar para as doses de nitrogênio de 0 , 40, 80 e $120 \mathrm{mg} \mathrm{dm}^{-3}$ os valores de 1,30; 1,$62 ; 1,94$ e de $2,26 \mathrm{~cm} /$ dia no capim-massai.

Os valores de comprimento e área da lâmina foliar observados para o capim-bermuda tifton 85 foram comparativamente mais próximos aos obtidos com gramíneas temperadas e relativamente inferiores aos determinados em gramíneas tropicais. Andrews et al. (1991) verificaram, quando as doses de nitrato variaram de 0,5 a $5,0 \mathrm{~mol} \mathrm{~m}^{-3}$, valores de 85 e $86 \mathrm{~mm}$ para comprimento final da folha e de 124 e 182 mm² $^{2}$ para área final da folha em festuca, enquanto, para azevém-perene, os valores respectivos foram de 91 e 90 mm e 132 e $176 \mathrm{~mm}^{2}$. Lawlor et al. (1989) reportaram, para a área foliar de trigo (Triticum aestivum), variação de 14,8 para $33,3 \mathrm{~cm}^{2}$ e de 3,1 para $35,3 \mathrm{~cm}^{2}$, quando as doses de nitrogênio foram de 0 e $200 \mathrm{~kg} \mathrm{ha}^{-1}$ e de 0,1 e $20 \mathrm{~mol} \mathrm{~m}^{-3} \mathrm{NO}^{-3}$, respectivamente. Herrera et al. (1991) constataram, para o Coastcross 1 bermudagrass, variação de 4,49 para 6,76 e para 9,25 cm² em doses de nitrogênio de 0, 100 e $200 \mathrm{~kg} \mathrm{ha}^{-1}$ na estação chuvosa. Wilman et al. (1977) constataram variação no comprimento de folha de 16,7 para 21,3 e para 23,2 cm e de 6,1 para 8,5 e para 9,4 cm² na área foliar de azevém-italiano considerando o intervalo entre cortes de quatro semanas para as doses de nitrogênio de 0, 262,5 e $525 \mathrm{~kg} \mathrm{ha}^{-1}$ para 30 semanas.

Garcez Neto et al. (2002) obtiveram, para comprimento da lâmina foliar (média de três alturas de corte), valores de 43,7; 48,9; 49,3 e $50 \mathrm{~cm}$ para as doses de nitrogênio de 0, 50, 100 e $200 \mathrm{mg} \mathrm{dm}^{-3}$, respectivamente, no capim-mombaça. Martuscello et al. (2005) com capim-xaraés e Martuscello et al. (2006) com capim-massai, observaram variação no comprimento foliar de 33,82 a $47,8 \mathrm{~cm}$ e de 17,4 a 31 , $48 \mathrm{~cm}$ para estes capins com as doses de nitrogênio de 0 e $120 \mathrm{mg} \mathrm{dm}^{-3}$, respectivamente, sendo esta variação associada ao regime de desfolhação imposto às plantas. A variação na área foliar com as doses de nitrogênio foi representada por regressão linear a partir da qual estimaram-se os valores de 2.047, 3.126, 4.206 e $5.285 \mathrm{~cm}^{2}$ e de 2.720, 3.897, $5.074,6.251 \mathrm{~cm}^{2}$ em função das doses de nitrogênio de 0,40 , 80 e $120 \mathrm{mg} \mathrm{dm}^{-3}$ para o capim-xaraés e o capim-massai, respectivamente. Fagundes et al. (2006) verificaram resposta linear positiva no comprimento foliar de Brachiaria decumbens com as doses de nitrogênio, a partir da qual foi possível calcular os valores de 15,16; 15,34; 15,51; 15,69 e 15,68 cm para as doses de nitrogênio de 100, 150, 200, 250 e $300 \mathrm{~kg} \mathrm{ha}^{-1}$, respectivamente. Silveira \& Monteiro (2007) obtiveram aumentos ajustados ao modelo quadrático de regressão para o efeito positivo das doses de nitrogênio na área foliar do capim-tanzânia. Megda \& Monteiro (2010) também observaram efeito do nitrogênio, este associado a doses de potássio, na área foliar do capim-marandu.

No primeiro crescimento, tanto os máximos valores estimados para comprimento da folha e área foliar quanto os valores correspondentes ao não-fornecimento de nitrogênio foram superiores aos do segundo crescimento, embora já se tenha observado alguma diminuição da primeira para a segunda avaliação. Esse fato pode estar associado à menor densidade e ao maior peso individual de perfilhos observado para o capim-bermuda tifton 85 (Premazzi et al., 2003) no primeiro crescimento. Neste ambiente, as folhas expressaram seus potenciais de crescimento em uma condição de menor competição por luz e nutrientes em comparação ao segundo crescimento. Mazzanti et al. (1994), em pastos de festuca do ano de 1987 para 1988, observaram que a densidade de perfilhos dobrou para relvados mantidos a equivalentes alturas ou índice de área foliar e, como consequência, a área foliar por perfilho ou o comprimento da folha por perfilho foi maior no primeiro (284 mm/perfilho) que no segundo ano de avaliação (213 mm/perfilho). De forma similar, Wilman \& Pearse (1984) constataram que o efeito positivo das doses de nitrogênio na massa de perfilhos esteve associado ao aumento no comprimento da lâmina foliar e no comprimento da bainha ( 0,$8 ; 4,3$ e 7,9 mg/perfilho e comprimento final da lâmina foliar de 6,5; 12,1 e 16,7 mm quando submetidos ao fornecimento de nitrogênio de 0,66 e $132 \mathrm{~kg} \mathrm{ha}^{-1}$, respectivamente).

Considerando que os máximos valores estimados para comprimento da folha e área foliar ocorreram em fornecimento similar de nitrogênio no solo nos dois períodos de crescimento, pode-se sugerir que houve menor 
direcionamento do nitrogênio para o crescimento das folhas no segundo período de crescimento. Esse modelo de partição do nitrogênio pode ser resultante da competição por nutrientes estabelecida pelos sítios ativos de crescimento na planta. Cruz \& Boval (1999) apontaram que tanto estolões quanto folhas em plantas estoloníferas representam sítios ativos de absorção de assimilados, o que pode conduzir à menor resposta de crescimento das folhas em caso de competição por nutrientes, como observado para o capim-bermuda tifton 85 no segundo crescimento.

Quando as máximas taxas de alongamento de folha são comparadas, maiores valores são observados no primeiro crescimento (59 e $65 \mathrm{~mm} /$ perfilho/2dias no primeiro crescimento e 52,47 e $55 \mathrm{~mm} /$ perfilho/2dias no segundo), o que pode estar associado a variações de temperatura nestes períodos $\left(38,5\right.$ e $21,3^{\circ} \mathrm{C}$ e de 34,8 e $15,7^{\circ} \mathrm{C}$, considerando os valores médios obtidos para a máxima e mínima temperaturas, no primeiro e segundo crescimentos, respectivamente). A temperatura de $15,7^{\circ} \mathrm{C}$ pode ter sido limitante para o crescimento das folhas, considerando que a temperatura ótima para a fotossíntese e para a atividade da fosfoenolpiruvato carboxilase em plantas $\mathrm{C}_{4}$ está entre $30-45^{\circ} \mathrm{C}$ e $30-35^{\circ} \mathrm{C}$, respectivamente (Hopkins, 1995). Taxa de expansão da folha associada a variações na temperatura também foi observada por Gastal et al. (1992) com festuca e por Baker \& Younger (1987) com azevém-perene.

Para a aplicação de nitrogênio sete dias após o corte, a expressão do potencial máximo de crescimento das folhas (comprimento e área foliares) ocorreu em doses de nitrogênio mais elevadas (entre 190 a $230 \mathrm{mg} \mathrm{kg}^{-1}$ ) em comparação à aplicação no momento do corte (entre $160 \mathrm{e}$ $180 \mathrm{mg} \mathrm{kg}^{-1}$ ). Essa resposta pode estar associada ao número de dias decorridos entre o fornecimento do nitrogênio e a avaliação do crescimento, com as plantas adubadas sete dias após o corte sendo avaliadas em fase mais ativa de absorção do nutriente.

\section{Conclusões}

No capim-bermuda tifton 85 há diminuição no fator de correção de área foliar com o fornecimento de nitrogênio. O nitrogênio proporciona variação positiva no comprimento foliar, na área da lâmina foliar e na taxa de alongamento da folha. A maior variação no crescimento das folhas em função do suprimento de nitrogênio ocorre entre a não-aplicação e a dose de $80 \mathrm{mg} \mathrm{kg}^{-1}$ de solo.

\section{Agradecimentos}

Aos engenheiros agrônomos Israel Benetti e Pelerson Furlan Schiavuzzo, pela valiosa colaboração na condução do experimento.

\section{Referências}

ALEXANDRINO, E.; NASCIMENTO JÚNIOR, D.; MOSQUIM, P.R. et al. Características morfogênicas e estruturais na rebrotação de Brachiaria brizantha cv. Marandu submetida a três doses de nitrogênio. Revista Brasileira de Zootecnia, v.33, p.1372-1379, 2004.

ANDREWS, M.; McKENZIE, B.A.; JONES, A.V. Nitrate effects on growth of the first four main stem leaves of a range of temperate cereals and pasture grasses. Annals of Botany, v.67, p.451-457, 1991.

BAKER, A-M.; YOUNGER, A. Factors affecting the leaf extension rate of perennial ryegrass in spring. Grass and Forage Science, v.42, p.381-390, 1987.

BÉLANGER, G. Morphogenetic characteristics of timothy grown with varying $\mathrm{N}$ nutrition. Canadian Journal of Plant Science, v.78, p.103-108, 1998.

CRUZ, P.; BOVAL, M. Effect of nitrogen on some morphogenetical traits of temperate and tropical perennial forage grasses. In: SIMPÓSIO INTERNACIONAL “GRASSLAND ECOPHYSIOLOGY AND GRAZING ECOLOGY”, 1., 1999, Curitiba. Anais... Curitiba: UFPR, 1999. p.134-150.

EMPRESA BRASILEIRA DE PESQUISA AGROPECUÁRIA. Centro Nacional de Pesquisa de Solos. Rio de Janeiro, Sistema brasileiro de classificação de solos. Brasília: Embrapa, Produção de Informação; Rio de Janeiro: Embrapa Solos, 1999. $42 \mathrm{p}$.

FAGUNDES, J.L.; FONSECA, D.M.; MISTURA, C. et al. Características morfogênicas e estruturais do capim-braquiária em pastagem adubada com nitrogênio avaliadas nas quatro estações do ano. Revista Brasileira de Zootecnia, v.35, p.21-29, 2006.

GARCEZ NETO, A.F.; NASCIMENTO JÚNIOR, D.; REGAZZI, A.J. et al. Respostas morfogênicas e estruturais de Panicum maximum cv. Mombaça sob diferentes níveis de adubação nitrogenada e alturas de corte. Revista Brasileira de Zootecnia, v.31, p.1890-1900, 2002.

GASTAL, F.; BELANGER, G.; LEMAIRE, G. A model of the leaf extension rate of tall fescue in response to nitrogen and temperature. Annals of Botany, v.70, p.437-442, 1992.

HERRERA, R.S.; HERNANDEZ, Y.; DORTA, N. Bermuda grass response to nitrogen fertilization and age of regrowth. 8 . Morphological development. Cuban Journal of Agricultural Science, v.25, p.291-296, 1991.

HOPKINS, W.G. Introduction to plant physiology. New York: John Wiley \& Sons, 1995. 464p.

KEMP, C.D. Methods of estimating the leaf area of grasses from linear measurements. Annals of Botany, v.24, p.491-499, 1960.

LAWLOR, D.W.; KONTTURI, M.; YOUNG, T. Photosynthesis by flag leaves of wheat in relation to protein, ribulose bisphosphate carboxylase activity and nitrogen supply. Journal of Experimental Botany, v.40, p.43-52, 1989.

MARTUSCELLO, J.A.; FONSECA, D.M.; NASCIMENTO JÚNIOR, D. et al. Características morfogênicas e estruturais do capim-Xaraés 
submetido à adubação nitrogenada e desfolhação. Revista Brasileira de Zootecnia, v.34, p.1475-1482, 2005.

MARTUSCELLO, J.A.; FONSECA, D.M.; NASCIMENTO JÚNIOR, D. et al. Características morfogênicas e estruturais do capim-massai submetido à adubação nitrogenada e desfolhação. Revista Brasileira de Zootecnia, v.35, p.665-671, 2006.

MAZZANTI, A.; LEMAIRE, G.; GASTAL, F. The effect of nitrogen fertilization upon the herbage production of tall fescue swards continuously grazed with sheep. 1. Herbage growth dynamics. Grass and Forage Science, v.49, p.111-120, 1994.

MEGDA, M.M.; MONTEIRO, F.A. Nitrogen and potassium supply and the morphogenic and productive characteristics of marandu palisadegrass. Revista Brasileira de Zootecnia, v.39, p.1666-1675, 2010.

PEARSE, P.J.; WILMAN, D. Effects of applied nitrogen on grass leaf initiation, development and death in field swards. Journal of Agricultural Science, v.103, p.405-413, 1984.

PREMAZZI, L.M.; MONTEIRO, F.A.; CORRENTE, J.E. Tillering of Tifton 85 bermudagrass in response to nitrogen rates and time of application after cutting. Scientia Agricola, v.60, p.565-571, 2003.

ROBSON, M.J.; DEACON, M.J. Nitrogen deficiency in small closed communities of S24 ryegrass. II. Changes in the weight and chemical composition of single leaves during their growth and death. Annals of Botany, v.42, p.1199-1213, 1978.

SCHIAVUZZO, P.F.; MONTEIRO, F.A.; CARMELLO, Q.A.C. et al. Determinação do fator de correção para estimativa da área foliar em braquiária Marandu, cultivada em doses de nitrogênio. In: SIMPÓSIO DE INICIAÇÃO CIENTIFICA DA UNIVERSIDADE DE SÃO PAULO, 6., 1998, São Paulo. Anais... São Paulo: EDUSP, 1998. v.1, p.498.

SILVEIRA, C.P.; MONTEIRO, F.A. Morfogênese e produção de biomassa do capim-Tanzânia adubado com nitrogênio e cálcio. Revista Brasileira de Zootecnia, v.36, p.335-342, 2007.

VOLENEC, J.J.; NELSON, C.J. Responses of tall fescue leaf meristems to $\mathrm{N}$ fertilization and harvest frequency. Crop Science, v.23, p.720-724, 1983.

WHITEHEAD, D.C. Grassland nitrogen. Wallingford: CAB International, 1995. 397p.

WILMAN, D.; PEARSE, P.J. Effects of applied nitrogen on grass yield, nitrogen content, tillers and leaves in field swards. Journal of Agricultural Science, v.103, p.201-211, 1984.

WILMAN, D.; DROUSHIOTIS, D.; MZAMANE, M.N. et al. The effect of interval between harvests and nitrogen application on initiation, emergence and longevity of leaves, longevity of tillers and dimensions and weights of leaves and “stems" in Lolium. Journal of Agricultural Science, v.89, p.65-79, 1977. 